\title{
Regulation of immune responses by the neonatal Fc receptor and its therapeutic implications
}

\author{
Timo Rath ${ }^{1,2}$, Kristi Baker ${ }^{1}$, Michal Pyzik ${ }^{1}$ and Richard S. Blumberg ${ }^{1,3}$ * \\ 1 Department of Medicine, Division of Gastroenterology, Brigham and Women's Hospital, Harvard Medical School, Boston, MA, USA \\ ${ }^{2}$ Department of Medicine, Division of Gastroenterology, Erlangen University Hospital, Friedrich Alexander University Erlangen-Nueremberg, Erlangen, Germany \\ ${ }^{3}$ Harvard Digestive Diseases Center, Boston, MA, USA
}

\section{Edited by:}

Jan Terje Andersen, Oslo University Hospital, Norway

\section{Reviewed by:}

Emma Slack, ETH Zürich, Switzerland

Tracey Lamb, Emory University

School of Medicine, USA

*Correspondence:

Richard S. Blumberg, Department of Medicine, Division of

Gastroenterology, Brigham and

Women's Hospital, Harvard Medical

School, 75 Francis Street, Thorn

Research Building 1419, Boston, MA 02115, USA

e-mail: rblumberg@partners.org
As a single receptor, the neonatal $F_{c}$ receptor $\left(F_{c} R n\right)$ is critically involved in regulating albumin and IgG serum concentrations by protecting these two ligands from degradation. In addition to these essential homeostatic functions, FcRn possesses important functions in regulating immune responses that are equally as critical and are increasingly coming to attention. During the first stages of life, FcRn mediates the passive transfer of IgG across the maternal placenta or neonatal intestinal walls of mammals, thereby conferring passive immunity to the offspring before and after birth. In fact, FcRn is one of the very few molecules that are known to move from luminal to serosal membranes of polarized cells that form epithelial barriers of the lung and intestines. Together with FcRn's recently explored critical role in eliciting MHC II presentation and $\mathrm{MHC}$ class I cross-presentation of IgG-complexed antigen, this renders FcRn capable of exerting broad and potent functions in regulating immune responses and immunosurveillance at mucosal sites. Further, it is now clear that FcRn dependent mucosal absorption of therapeutic molecules is a clinically feasible and potent novel route of non-invasive drug delivery, and the interaction between FcRn and IgG has also been utilized for the acquisition of humoral immunity at mucosal sites. In this review, we begin by briefly summarizing the basic knowledge on FcRn expression and IgG binding, then describe more recent discoveries pertaining to the mechanisms by which FCRn orchestrates IgG related mucosal immune responses and immunosurveillance at host-environment interfaces within the adult organism. Finally, we outline how the knowledge of actions of FcRn at mucosal boundaries can be capitalized for the development and engineering of powerful mucosal vaccination strategies and novel routes for the non-invasive delivery of Fc-based therapeutics.

Keywords: neonatal Fc receptor, immunoglobulin G, albumin, mucosal immunology, antigen presentation

\section{FcRn BINDS IgG MOLECULES THROUGHOUT ADULT LIFE}

FcRn, encoded by the Fcgrt gene, is an MHC class I-like transmembrane protein that requires non-covalent association with $\beta 2$-microglobulin $(\beta 2-\mathrm{m})$ for proper functioning. In its best known function, $\mathrm{FcRn}$ binds to the $\mathrm{CH} 2-\mathrm{CH} 3$ interface of the IgG Fc region in a 2:1 stoichiometry (1-3). Binding between IgG and FcRn occurs in a strictly pH-dependent manner with micro- to nanomolar affinity at $\mathrm{pH} 6.5$ while binding is virtually absent at $\mathrm{pH} 7.5(4,5)$. As revealed by site-directed mutagenesis, the residues Ile253, His 310 , and His435 of IgG are critically involved in its interaction with FcRn $(4,6-8)$. Consistent with such strict $\mathrm{pH}$-dependent binding, the bulk of FcRn is expressed intracellularly - predominantly in endosomes - and such that the interaction between FcRn and its ligands occurs within an intracellular acidic milieu (9-12). Although originally viewed as a receptor restricted to neo- and antenatal life, it is now clear that FcRn continues to function throughout adult life and is expressed lifelong in both parenchymal cells (epithelium of the lung and intestine as well as the liver and vascular endothelium) and hematopoietic cells [monocytes, macrophages, dendritic cells (DCs), polymorphonuclear leukocytes, and B cells] in mouse and humans [as reviewed elsewhere (13-17)]. Apart from regulating and extending the serum half-life of IgG by a mechanism that is operative in DCs and endothelial cells (18-21), FcRn orchestrates IgG-based immune responses at mucosal sites. Collectively, the numerous functions of FcRn enable it to act as a sensitive regulator of mucosal immunity via bidirectional transcytosis of IgG and luminal antigens across epithelial boundaries as well as the active induction of MHC II presentation and MHC I crosspresentation pathways for the generation of antigen-specific $\mathrm{T}$-cell responses.

\section{MUCOSAL IMMUNE REGULATION AND IMMUNOSURVEILLANCE BY FCRn}

Apart from being responsible for the transplacental transfer of maternal IgG to a human fetus, FcRn has been shown to mediate the bidirectional transport of IgG across all polarized epithelial barriers including those of the gastrointestinal and respiratory tract, the placenta, and the genitourinary system including kidneys $(8,22-29)$. Further, it has been documented that this mechanism is operative not only in humans and mice but also in rats, pigs, and non-human primates, implying that the transepithelial 
IgG transport across mucosal membranes is an evolutionarily well conserved and thus important part of immune regulation. By expressing FcRn, the epithelial barrier thus gains the ability to transport IgG from the basolateral to the apical side and vice versa, or, in other words, to deliver IgG into the lumen from the tissue space and, subsequently, transport IgG-bound luminal antigens back to the lamina propria (LP). This process is of utmost importance for immune regulation at mucosal barriers and in vivo studies have impressively demonstrated that FcRn is indeed a key molecule in integrating humoral and cellular immunity and intraluminal (and thereby foreign) signals into the host intramural immune system. To mirror the situation in humans, these studies utilized humanized mice in which a human FcRn transgene (together with human $\beta 2-\mathrm{m}$ ) was expressed in a mouse that was devoid of mouse FcRn $(30,31)$. In vivo studies using the model antigen ovalbumin (OVA) demonstrated that after intravenous injection of anti-OVA IgG and subsequent oral feeding of fluorescently labeled OVA, OVA-IgG immune complexes (ICs) formed within the gastrointestinal lumen and were transported in an FcRn dependent manner into the LP where the antigen-antibody complex was taken up by CD11c ${ }^{+}$DCs which, upon MHC II presentation of OVA epitopes, were then able to induce an antigen-specific $\mathrm{CD} 4^{+} \mathrm{T}$-cell response $(31)$. Of note, the mechanism of FcRn-mediated transfer of antigen-specific IgG and subsequent induction of an antigen-specific T-cell response was not limited to the intestinal tract, as nasal administration of OVA after intravenous injection of anti-OVA IgG led to a similar FcRn-mediated uptake of antigen-antibody ICs and an expansion of antigen-specific CD4 ${ }^{+}$T-cells in the nasal-associated lymphatic tissue (31). This mechanism has direct physiologic and immunopathogenic relevance: when challenged with Citrobacter rodentium - which models enteropathogenic Escherichia coli infection - mice with restricted expression of FcRn solely within the intestinal epithelium, but not FcRn deficient animals, were protected from infection but only in the presence of anti- $C$. rodentium IgG antibodies, consistent with IgG being a main effector molecule in the eradication of this pathogen (32-34). To mount an effective immune response against this epithelial pathogen, FcRn was shown to mediate the following processes (Figure 1): (I.) transport of pathogen-specific IgG from the systemic circulation across the epithelial barrier into the intestinal lumen, (II.) uptake of the newly formed ICs consisting of bacteria and anti-bacterial IgG and transcytosis of these into the LP, and (III.) induction of an antigen-specific immune response and T-cell expansion within regional lymphoid structures and associated peripheral tissues (34).
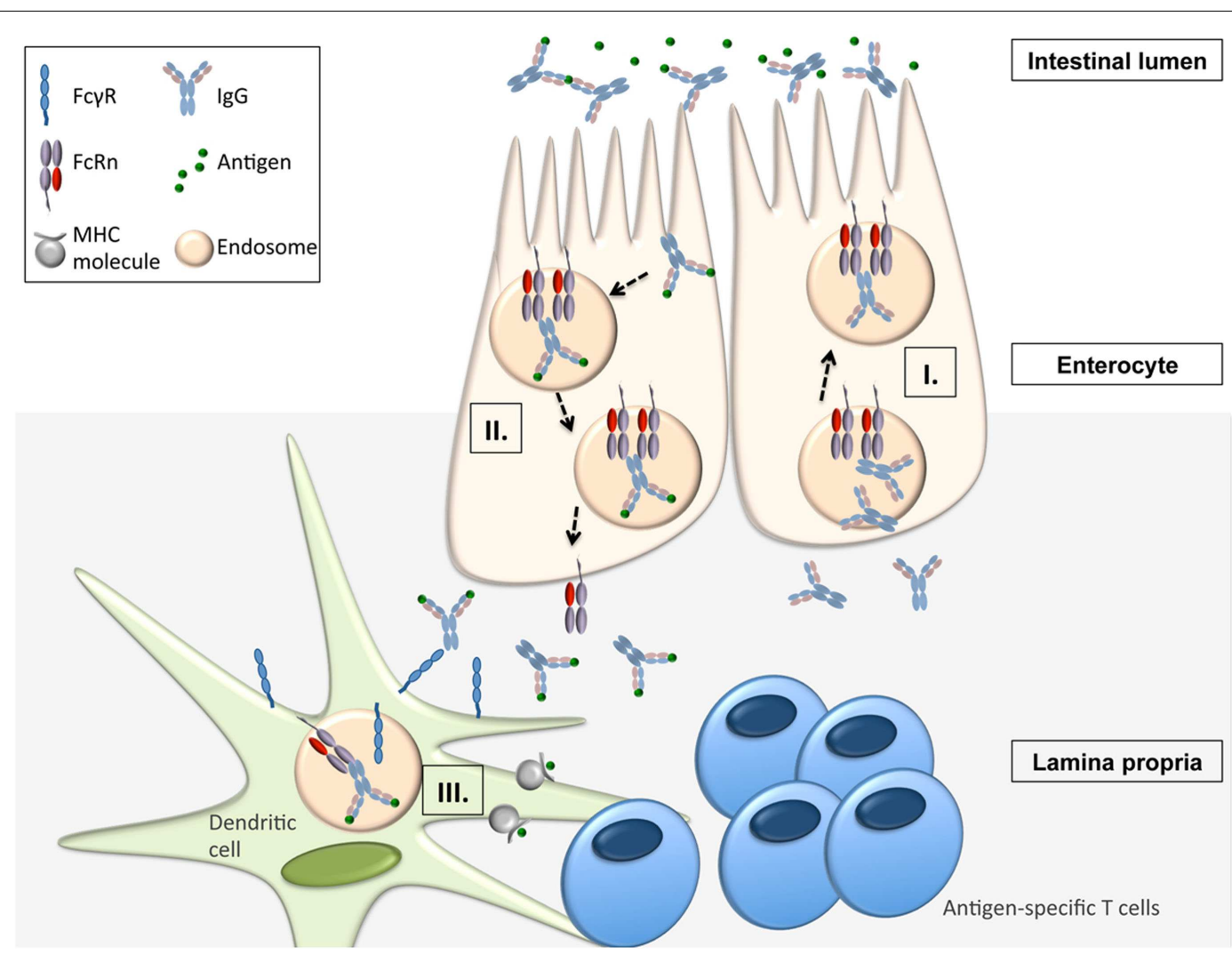

FIGURE 1 | FcRn-mediated functions in immune surveillance and homeostasis at the intestinal epithelial barrier $(16,31,34)$. FCRn within enterocytes can transport IgG from the systemic circulation across the epithelial barrier into the intestinal lumen (I.). Upon formation of immune complexes (ICs) consisting of bacteria and anti-bacterial IgG within the intestinal lumen, FcRn can transcytose these back into the LP (II.). In the LP, the ICs are delivered to antigen-presenting cells (APCs) from which the ICs are taken up via canonical Fc $\gamma R^{\prime}$ s. Once internalized into the cell, the ICs are then directed into acidic endosomes, in which $\mathrm{FcRn}$ is operative to mediate the presentation of IC derived antigen to antigen-specific T-cells (III.). 
Thus, these studies provide direct evidence that epithelial expression of FcRn is able to link luminal and/or epithelial infectious exposures with systemic immune activation. FcRn expression in the gastric epithelium and the associated transport of pathogen-specific IgG across the gastric epithelium is also linked to the prevention of gastric colonization and invasion by the pathogens Helicobacter heilmannii and Helicobacter pylori (35). Similarly, FcRn within the genitourinary and respiratory tract enables the transmucosal transport of pathogen-specific IgG and has been associated with the prevention of viral infection, as shown in model studies mirroring herpes simplex 2 or influenza infection $(24,29)$.

\section{FCRn'S ROLE IN ANTIGEN PRESENTATION BY PROFESSIONAL ANTIGEN-PRESENTING CELLS AT MUCOSAL SURFACES}

CLASSICAL MHC II PRESENTATION OF IMMUNE COMPLEXED ANTIGEN

While the later studies mainly investigated FcRn's function of providing passive immunity by transcytosing IgG across the mucosal barrier, the discoveries that FcRn within the DC is deeply involved in the generation of antigen-specific T-cell responses opened up another dimension in FcRn's pleiotropic functions for immune homeostasis. One critical prerequisite for addressing FcRn's role in antigen presentation is to carefully control IgG levels. Both hematopoietic cells and parenchymal cells are equally responsible for protecting IgG from degradation (18-21, 30), and in order to account for IgG deficiency in $\mathrm{Fcgrt}^{-1-}$ mice, the utilization of bone-marrow chimeric mice is an elegant approach to circumvent differences in IgG levels between WT and Fcgrt ${ }^{-1-}$ mice, as previously shown $(18,19,21)$.

After having shown that FcRn is expressed in professional APC in human and mouse $(18,19,21,31,36-38)$, it was demonstrated that FcRn in DCs enhances MHC II antigen presentation and induces proliferation of antigen-specific CD4 ${ }^{+}$T-cells when antigen is presented as a multimeric IC with $\operatorname{IgG}$, both in vitro and in vivo (21), and this observation was also confirmed in humans (39). Furthermore, both murine and human studies have demonstrated that ICs containing a non-FcRn-binding IHH-IgG mutant, which harbors three mutations that disable binding to FcRn (I253A, H435A, and H436A) (7), do not lead to T-cell activation (21). Importantly, the studies showed that this regulation is only observed when the IgG-antigen complex is provided as a multimeric IC, suggesting that FcRn directs the intracellular trafficking of its ligands differently depending on the valency of the bound ligands. This concept was supported by confocal microscopy showing that multimeric IgG ICs, but not IHH-IgG1 ICs or monomeric ICs, were rapidly internalized by human DCs and co-localized with FcRn first in membrane-proximal intracellular compartments, presumably early endosomes, and subsequently in LAMP1-positive lysosomes, thus indicating that FcRn directs multimeric ICs into a cellular compartment equipped with the machinery to induce MHC II antigen presentation (39). Using bone-marrow chimeric mice, it was then directly shown that the fate and also the associated serum half-life are indeed fundamentally different depending on the ligand valency. IgG present in multimeric ICs exhibited rapidly increased degradation mediated by hematopoietic cells, presumably DCs, consistent with an in vivo fate of active trafficking toward lysosomal degradation rather than FcRn-mediated recycling. However, unbound IgG or IgG in monomeric complexes were protected from degradation in an FcRn dependent manner from both hematopoietic and myeloid cells (39). Thus, these studies show that FcRn determines the fate of IgG depending on the nature of the ligand. In a more general sense, these findings illustrate that FcRn actively senses whether an antigen has already been IgG opsonized, in which case the IC are routed towards antigen presentation compartments, or whether IgG is unbound and thus should be protected from degradation.

\section{MHC I CROSS-PRESENTATION OF IMMUNE COMPLEXED ANTIGEN}

Recent studies further extend the understanding of the critical involvement of FcRn in antigen presentation at mucosal surfaces. Strikingly, CD8 ${ }^{-} \mathrm{CD} 11 \mathrm{~b}^{+}$DCs loaded with IgG-complexed OVA induced robust proliferation of adoptively transferred OT-I T-cells in an entirely FcRn-dependent manner (36). These studies were the first to discover that FcRn exhibits also a fundamental role in the presentation of exogenous antigen to $\mathrm{CD} 8^{+} \mathrm{T}$-cells, a process called cross-presentation $(36,40)$. These studies also demonstrated that FcRn within $\mathrm{CD}^{-} \mathrm{CD} 11 \mathrm{~b}^{+}$DCs directed the IgG ICs into a Rab27a, vacuolar ATPase, and gp91phox containing acidic phagosome that allowed for cross-presentation (36). Further, utilizing antibodies that have no affinity for FcRn, but intact affinity for canonical Fc $\gamma$ Rs (IHH-IgG) or which cannot bind Fc $\gamma$ Rs, but retain the ability to bind FcRn [N297A-IgG (41)], it was shown that canonical Fc $\gamma$ Rs on the surface of DCs mediate the entry of the ICs into the cell which then are further directed and trafficked in an FcRn dependent fashion as outlined above (36). Thus, FcRn and canonical surface Fc $\gamma$ R's cooperate in inducing antigen presentation and the $\mathrm{pH}$-dependent ligand binding of FcRn and its expression within the acidic milieu of endosomal compartments is perfectly suited to further handle, traffic and process IgG and ICs once bound at neutral $\mathrm{pH}$ by $\mathrm{Fc} \gamma \mathrm{Rs}$ and internalized.

The mechanisms and pathophysiological significance of FcRn dependent cross-presentation to DCs at mucosal surfaces has recently been analyzed (37). First, these studies demonstrated that untreated $\mathrm{Fcgrt}^{-1-}$ mice exhibit decreased numbers of $\mathrm{CD}{ }^{+}$ T-cells within the LP of the large intestine, and that these were also deficient in cytokine production. The utilization of CD11 ${ }^{\mathrm{Cre}} \mathrm{Fcgrt}{ }^{\mathrm{Fl} / \mathrm{Fl}}$ mice (37) has shown that FcRn expression in DCs is critical for this. Second, FcRn within DCs was not only shown to be required for homeostatic $\mathrm{CD} 8^{+} \mathrm{T}$-cell activation but also conferred protection from cancer development at mucosal sites, namely, the large intestine and the lung. This was reliant on the FcRn dependent induction of endogenous $\mathrm{CD}^{+}{ }^{+} \mathrm{T}$-cells towards cognate tumor antigens, and thus, these studies were the first to identify a deep involvement of FcRn in the protection from cancers arising at mucosal tissues. As an additional mechanism behind these observations, cross-linking of FcRn by IgG IC induced secretion of the cytotoxicity-promoting cytokine IL-12, thereby providing an additional stimulus to activate antigenically primed specific $\mathrm{CD}^{+}$T-cells (37). Importantly, analysis of the overall microbial community composition and diversity from wildtype and $\mathrm{Fcgrt}^{-1-}$ littermates revealed no significant differences in either post-weaning, 8-week-old mice or pre-weaning, 2 -week-old mice in any of three separate intestine-associated tissue 
compartments, thereby confirming that the induction of mucosal $\mathrm{CD}^{+} \mathrm{T}$-cells in FcRn bearing mice was not due to changes in the intestinal microbiota (37).

These findings are directly translatable to human pathology such that human DCs expressing high levels of FcRn co-localize with $\mathrm{CD} 8^{+}$T-cells in the stroma of both normal and colorectal cancer (CRC) large intestine and induce IL-12 production in an FcRn-dependent manner. Further, survival analysis indicated that CRC patients with $\geq 10 \mathrm{FcRn}^{+} \mathrm{CD} 11 \mathrm{c}^{+}$cells per observed area had significantly longer survival times over a 70-month follow up than did those with $<10 \mathrm{FcRn}^{+} \mathrm{CD}_{11 \mathrm{c}^{+}}$cells in the tumor microenvironment (37). Finally, this mechanism was shown to be amenable to therapeutic manipulation. When ICs were formed with an engineered IgG variant known to exhibit enhanced FcRn binding with maintained $\mathrm{pH}$ dependency (42), antigen-specific $\mathrm{CD}^{+} \mathrm{T}$-cell activation was induced at antigen concentrations 10 -fold lower than that observed with native IgG IC, thereby demonstrating that targeting the immunostimulatory potential of FcRn using complexes formed with IgG variants having increased FcRn binding (15) and which are restricted to a single defined tumor antigen is a tractable and effective anti-tumor therapeutic approach (37). Further, proof-of-principle experiments demonstrated that ex vivo priming of $\mathrm{CD}^{+}$T-cells towards a single FcRn-targeted antigen expressed by tumor cells enables subsequent in vivo protection from the seeding of lung metastases. These studies demonstrate the potential of therapeutically promoting tumor immune surveillance in healthy, high-risk individuals by enhancing the baseline cytotoxic potential of the intestine by targeting and modulating FcRn binding to IgG (37).

\section{FcRn DEPENDENT NON-INVASIVE MUCOSAL DRUG DELIVERY AND MUCOSAL VACCINATION STRATEGIES}

FcRn is one of the few molecules known to move from the luminal to serosal membranes of the polarized cells that form the epithelial barriers of the lung and intestine $(16,43)$, thereby providing unique opportunities for potent non-invasive delivery of protein therapeutics across mucosal interfaces. This non-invasive mucosal drug delivery approach capitalizes upon two important prerequisites: (i) the knowledge that FcRn is functionally expressed throughout adult life in the upper and central airways as well as intestines of humans and non-human primates $(8,9,44,45)$ (ii) the knowledge that FcRn binds to the Fc portion of IgG in a $\mathrm{pH}$-dependent manner and prevents degradation of monomeric ligand. Thus, when linked to an Fc fragment, therapeutic molecules benefit from both FcRn dependent half-life extension (15) and also mucosal absorption across epithelial boundaries.

The first study successfully demonstrating FcRn dependent delivery of an Fc containing therapeutic was performed in mice with a fusion protein between mouse erythropoietin (Epo) and the Fc fragment of mouse IgG1, showing that bioactive Fc-Epo fusion protein was successfully absorbed FcRn dependently via the respiratory epithelium (8). In subsequent studies in non-human primates, pulmonary delivery of a human Epo Fc-fusion protein was also successfully accomplished when the fusion proteins were aerosolized with a particle size of 4-6 $\mathrm{mm}$ to target the upper airways (44). In both mice and monkeys, the FcRn-dependence of this transepithelial transport was proven by the demonstration that an EpoFc-fusion containing the non-FcRn binding IHH variant of IgG was only poorly absorbed (44). In addition to that, it has already been demonstrated that this pathway is also operative in humans. A phase I clinical trial assessing the efficacy of the delivery of an Epo Fc-fusion protein into the bloodstream after administration of the fusion protein in the upper airways was able to show a dose-dependent uptake of the fusion protein with retained biologic activity (46). These studies laid the foundation for the broader possibility of transepithelial delivery of different types of Fc-fused macromolecular cargo including interferon$\alpha$, interferon- $\beta$, follicle-stimulating hormone, and nanoparticles (47-50). Thus, these studies demonstrate that FcRn-dependent drug delivery across mucosal surfaces is a novel non-invasive delivery approach that is both potent and clinically feasible.

Interestingly, exploitation of this mechanism is not necessarily restricted to the adult organism. Using a murine model of beta-glucuronidase (GUS) deficiency, in which glycosaminoglycan storage begins in prenatal life, it was shown that a GUS-Fc-fusion protein, infused into the mothers, was transported across the placenta into the fetus, leading to reduced lysomal storage disease only in those mice whose mothers were administered GUS-Fc (51). While this approach outline that FcRn binding to the Fc region of IgG might be exploited in severe cases for the administration of Fc-based treatment strategies starting in utero, these studies clearly imply that pathogenic antibodies can also cross the maternalfetal barrier. That this is indeed the case has been shown in a murine model of fetal and neonatal immune thrombocytopenia (FNIT) in which FcRn-mediated transplacental transfer of maternal pathogenic antibodies results in the destruction of platelets in the neonate (52) but saturation of FcRn by intravenous infusion of IgG (IVIG) or blocking of FcRn in the mother prevented antibody-mediated FNIT (53). Apart from pathogenic antibodies, virion-IgG complexes, as demonstrated for cytomegalovirus, can disseminate in the placenta and gain access to the fetal circulation by co-opting the FcRn-mediated transplacental IgG transport pathway (54). Collectively, these studies demonstrate that the relevance of FcRn's functions in the placenta extend far beyond the simple acquisition of passive immunity but also have broad implications for understanding neonatal (patho)immunology and the development of novel treatment strategies.

As shown recently, the interaction between FcRn and IgG can not only be co-opted for novel and non-invasive drug delivery approaches but also for the induction of humoral immunity along mucosal barriers. FcRn's ability to confer humoral immunity is based on its capacity to bidirectionally transcytose IgG molecules across the epithelium lining mucosal barriers and preliminary studies have successfully demonstrated that FcRn conferred protective passive humoral immunity against infections at the site of pathogen entry when neutralizing antibodies were administered to the systemic circulation before infection $(24,29,35)$. This was shown in vivo for both bacterial and viral agents, where FcRnmediated translocation of systemically administered pathogenspecific IgG to the mucosal site of pathogen entry within the gastrointestinal or genital tract was identified as the key mechanism responsible for protection $(24,29,35)$.

In addition to passive immunity, it has already been demonstrated in vivo that FcRn can also confer active humoral immunity. 
Table 1 |Therapeutic applications and opportunities derived from FcRn-based biology.

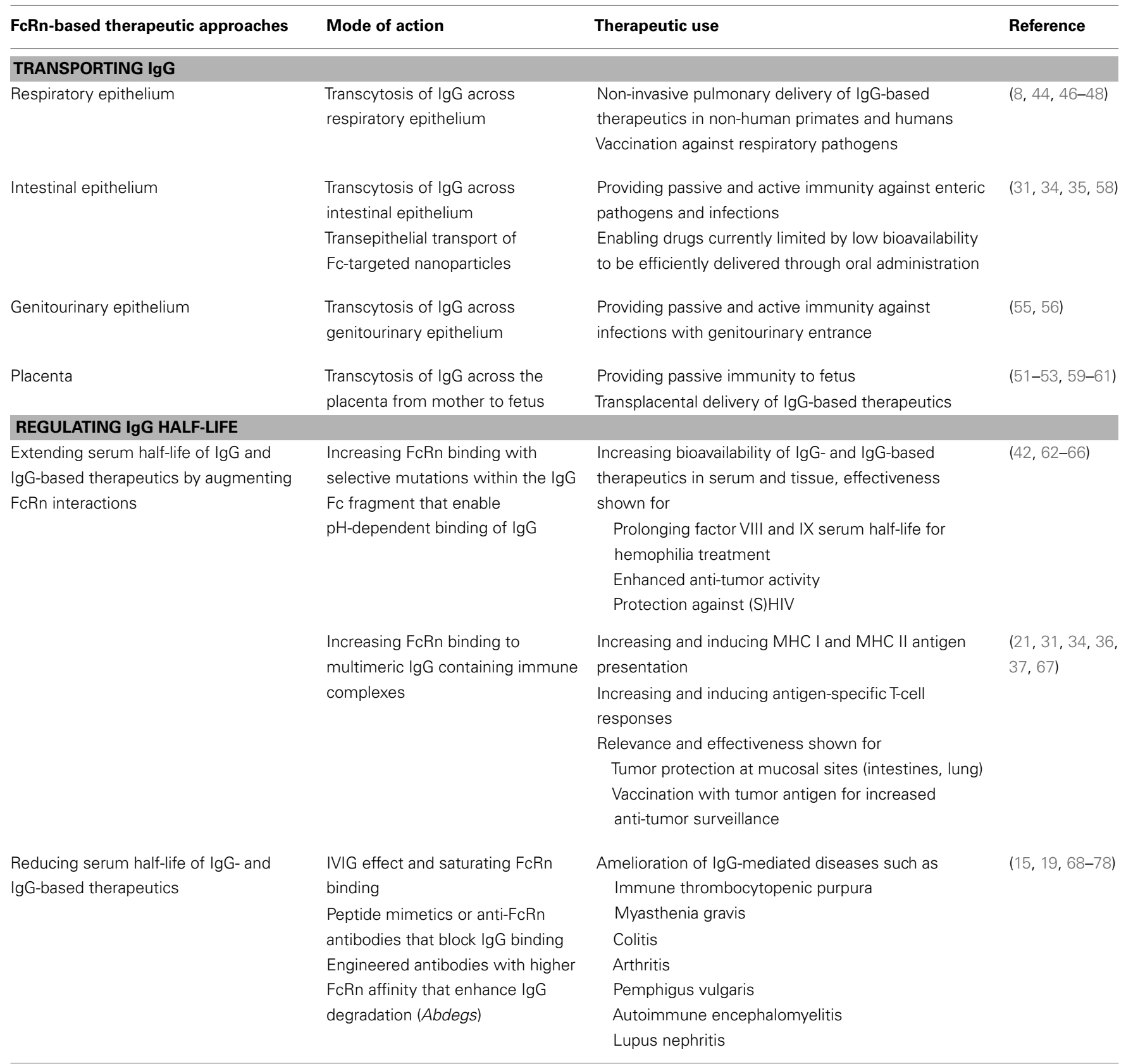

A prerequisite in these studies was that pathogens were, in order to enable FcRn-mediated transport of the antigen across the mucosal barrier, presented as Fc-fusion proteins and were administered in the presence of potent adjuvants to force an immune response. Intranasal immunization with a fusion protein between herpes simplex virus type-2 (HSV-2) glycoprotein gD and the Fc domain of IgG2a together with the adjuvant CpG, protected wild type, but not FcRn knockout, mice after intravaginal challenge with virulent HSV-2 and this immunization strategy induced an efficient mucosal and systemic antibody response as well B- and T-cell immunity (55). Similarly, mice that were intranasally vaccinated with a fusion protein between HIV Gag p24 and the Fc of mouse IgG2a together with $\mathrm{CpG}$ as an adjuvant developed local and systemic immunity, including durable B- and T-cell memory. In these experiments, Gag-specific immunity was sufficiently potent to protect against an intravaginal challenge with recombinant vaccine virus expressing the HIV Gag protein (56). Of particular importance, mice lacking FcRn or those immunized with free antigen or an antigen fused to an Fc fragment disabled in FcRn binding were not protected against HSV or HIV infection, thereby highlighting the central role of FcRn and its intact binding to IgG for efficient mucosal transport across an epithelial barrier and the elicitation of active mucosal immunization $(55,56)$. Finally, as shown in transgenic animals, overexpression of FcRn 
can significantly enhance humoral immunity by the following mechanisms: (i) prolonged IgG half-life, (ii) facilitation of antigen presentation by antigen-presenting cells (APCs), resulting in increased antigen-specific humoral immune response with larger numbers of antigen-specific B cells, and (iii) generation of antibodies against weakly immunogenic antigens, as recently reviewed elsewhere (57). Table 1 summarizes therapeutic applications and opportunities derived from FcRn-based biology.

\section{CONCLUDING REMARKS}

In the recent past, the view of FcRn has changed from a receptor, which contributes to passive immunity via transcytosis of IgG molecules to that of an active signaling and trafficking receptor that is deeply involved in antigen presentation pathways. It is now clear that FcRn inherits a fundamental role in classical MHC II presentation of exogenous antigen as well in the cross-presentation of exogenous antigen on MHC I molecules. The pleiotropic functions enable FcRn to elicit antigen-specific $\mathrm{CD} 4^{+}$and $\mathrm{CD} 8^{+} \mathrm{T}$-cell responses and thus exert broad functions in immune surveillance and immune homeostasis. Critically, these pathways have already been shown to have important pathophysiological relevance for infectious diseases and cancer development along mucosal barriers. Exploitation of the receptor-ligand interaction between FcRn and IgG has already been successfully used for the development of novel mucosal vaccination strategies as well as the non-invasive delivery of Fc-fusion proteins. Thus, the roles that FcRn plays in guiding the transport of IgG across epithelial barriers and regulating the recycling of monomeric IgG away from a degradative fate in lysosomes and preserving IgG half-life or alternatively directing IgG containing ICs to the antigen presentation machinery present enormous therapeutic opportunities for translation (Table 1). Our increasing understanding of the biology of FcRn will likely only increase the range of therapeutic applications for FcRn-targeted drugs, which promise to deliver effective treatment for neoplastic, infectious, and autoimmune diseases.

\section{REFERENCES}

1. Huber AH, Kelley RF, Gastinel LN, Bjorkman PJ. Crystallization and stoichiometry of binding of a complex between a rat intestinal Fc receptor and Fc. J Mol Biol (1993) 230:1077-83. doi:10.1006/jmbi.1993.1220

2. Sanchez LM, Penny DM, Bjorkman PJ. Stoichiometry of the interaction between the major histocompatibility complex-related Fc receptor and its Fc ligand. Biochemistry (1999) 38:9471-6. doi:10.1021/bi9907330

3. Schuck P, Radu CG, Ward ES. Sedimentation equilibrium analysis of recombinant mouse FcRn with murine IgG1. Mol Immunol (1999) 36:1117-25. doi:10.1016/S0161-5890(99)00093-0

4. Raghavan M, Bonagura VR, Morrison SL, Bjorkman PJ. Analysis of the $\mathrm{pH}$ dependence of the neonatal $\mathrm{Fc}$ receptor/immunoglobulin $\mathrm{G}$ interaction using antibody and receptor variants. Biochemistry (1995) 34:14649-57. doi:10.1021/ bi00045a005

5. Raghavan M, Chen MY, Gastinel LN, Bjorkman PJ. Investigation of the interaction between the class I MHC-related Fc receptor and its immunoglobulin G ligand. Immunity (1994) 1:303-15. doi:10.1016/1074-7613(94)90082-5

6. Medesan C, Cianga P, Mummert M, Stanescu D, Ghetie V, Ward ES. Comparative studies of rat IgG to further delineate the Fc:FcRn interaction site. Eur J Immunol (1998) 28:2092-100. doi:10.1002/(SICI) 1521-4141(199807)28:07<2092::AIDIMMU2092>3.0.CO;2-E

7. Medesan C, Matesoi D, Radu C, Ghetie V, Ward ES. Delineation of the amino acid residues involved in transcytosis and catabolism of mouse IgG1. J Immunol (1997) 158:2211-7.

8. Spiekermann GM, Finn PW, Ward ES, Dumont J, Dickinson BL, Blumberg RS, et al. Receptor-mediated immunoglobulin $\mathrm{G}$ transport across mucosal barriers in adult life: functional expression of FcRn in the mammalian lung. J Exp Med (2002) 196:303-10. doi:10.1084/jem.20020400

9. Dickinson BL, Badizadegan K, Wu Z, Ahouse JC, Zhu X, Simister NE, et al. Bidirectional FcRn-dependent IgG transport in a polarized human intestinal epithelial cell line. J Clin Invest (1999) 104:903-11. doi:10.1172/JCI6968

10. Ober RJ, Martinez C, Vaccaro C, Zhou J, Ward ES. Visualizing the site and dynamics of IgG salvage by the MHC class I-related receptor, FcRn. J Immunol (2004) 172:2021-9. doi:10.4049/jimmunol.172.4.2021

11. Ward ES, Martinez C, Vaccaro C, Zhou J, Tang Q, Ober RJ. From sorting endosomes to exocytosis: association of Rab4 and Rab11 GTPases with the Fc receptor, FcRn, during recycling. Mol Biol Cell (2005) 16:2028-38. doi:10.1091/mbc.E04-08-0735

12. Ward ES, Zhou J, Ghetie V, Ober RJ. Evidence to support the cellular mechanism involved in serum IgG homeostasis in humans. Int Immunol (2003) 15:187-95. doi:10.1093/intimm/dxg018

13. Andersen JT, Sandlie I. The versatile MHC class I-related FcRn protects IgG and albumin from degradation: implications for development of new diagnostics and therapeutics. Drug Metab Pharmacokinet (2009) 24:318-32. doi:10.2133/dmpk.24.318

14. Baker K, Rath T, Pyzik M, Blumberg RS. The role of FcRn in antigen presentation. Front Immunol (2014) 5:408. doi:10.3389/fimmu.2014.00408

15. Rath T, Baker K, Dumont JA, Peters RT, Jiang H, Qiao SW, et al. Fc-fusion proteins and FcRn: structural insights for longer-lasting and more effective therapeutics. Crit Rev Biotechnol (2013). doi:10.3109/07388551.2013.834293

16. Rath T, Kuo TT, Baker K, Qiao SW, Kobayashi K, Yoshida M, et al. The immunologic functions of the neonatal Fc receptor for IgG. J Clin Immunol (2013) 33(Suppl 1):S9-17. doi:10.1007/s10875-012-9768-y

17. Roopenian DC, Akilesh S. FcRn: the neonatal Fc receptor comes of age. Nat Rev Immunol (2007) 7:715-25. doi:10.1038/nri2155

18. Akilesh S, Christianson GJ, Roopenian DC, Shaw AS. Neonatal FcR expression in bone marrow-derived cells functions to protect serum IgG from catabolism. J Immunol (2007) 179:4580-8. doi:10.4049/jimmunol.179.7.4580

19. Kobayashi K, Qiao SW, Yoshida M, Baker K, Lencer WI, Blumberg RS. An FcRndependent role for anti-flagellin immunoglobulin $\mathrm{G}$ in pathogenesis of colitis in mice. Gastroenterology (2009) 137(1746-1756):e1741. doi:10.1053/j.gastro. 2009.07.059

20. Montoyo HP, Vaccaro C, Hafner M, Ober RJ, Mueller W, Ward ES. Conditional deletion of the MHC class I-related receptor FcRn reveals the sites of IgG homeostasis in mice. Proc Natl Acad Sci USA (2009) 106:2788-93. doi:10.1073/pnas.0810796106

21. Qiao SW, Kobayashi K, Johansen FE, Sollid LM, Andersen JT, Milford E, et al. Dependence of antibody-mediated presentation of antigen on FcRn. Proc Natl Acad Sci U S A (2008) 105:9337-42. doi:10.1073/pnas.0801717105

22. Akilesh S, Huber TB, Wu H, Wang G, Hartleben B, Kopp JB, et al. Podocytes use FcRn to clear IgG from the glomerular basement membrane. Proc Natl Acad Sci U S A (2008) 105:967-72. doi:10.1073/pnas.0711515105

23. Antohe F, Radulescu L, Gafencu A, Ghetie V, Simionescu M. Expression of functionally active FcRn and the differentiated bidirectional transport of IgG in human placental endothelial cells. Hum Immunol (2001) 62:93-105. doi:10.1016/S0198-8859(00)00244-5

24. Bai Y, Ye L, Tesar DB, Song H, Zhao D, Björkman PJ, et al. Intracellular neutralization of viral infection in polarized epithelial cells by neonatal $\mathrm{Fc}$ receptor $(\mathrm{FcRn})$ mediated IgG transport. Proc Natl Acad Sci U S A (2011) 108(45):18406-11. doi:10.1073/pnas.1115348108

25. Claypool SM, Dickinson BL, Wagner JS, Johansen FE, Venu N, Borawski JA, et al. Bidirectional transepithelial IgG transport by a strongly polarized basolateral membrane Fcgamma-receptor. Mol Biol Cell (2004) 15:1746-59. doi:10.1091/mbc.E03-11-0832

26. Claypool SM, Dickinson BL, Yoshida M, Lencer WI, Blumberg RS. Functional reconstitution of human $\mathrm{FcRn}$ in Madin-Darby canine kidney cells requires co-expressed human beta 2-microglobulin. J Biol Chem (2002) 277:28038-50. doi:10.1074/jbc.M202367200

27. Ellinger I, Rothe A, Grill M, Fuchs R. Apical to basolateral transcytosis and apical recycling of immunoglobulin $\mathrm{G}$ in trophoblast-derived BeWo cells: effects of low temperature, nocodazole, and cytochalasin D. Exp Cell Res (2001) 269:322-31. doi:10.1006/excr.2001.5330

28. Ellinger I, Schwab M, Stefanescu A, Hunziker W, Fuchs R. IgG transport across trophoblast-derived BeWo cells: a model system to study IgG transport in the placenta. Eur J Immunol (1999) 29:733-44. doi:10.1002/(SICI)15214141(199903)29:03<733::AID-IMMU733>3.0.CO;2-C 
29. Li Z, Palaniyandi S, Zeng R, Tuo W, Roopenian DC, Zhu X. Transfer of IgG in the female genital tract by MHC class I-related neonatal $\mathrm{Fc}$ receptor $(\mathrm{FcRn}) \mathrm{con}$ fers protective immunity to vaginal infection. Proc Natl Acad Sci U S A (2011) 108:4388-93. doi:10.1073/pnas.1012861108

30. Roopenian DC, Christianson GJ, Sproule TJ, Brown AC, Akilesh S, Jung N, et al. The MHC class I-like IgG receptor controls perinatal IgG transport, IgG homeostasis, and fate of IgG-Fc-coupled drugs. J Immunol (2003) 170:3528-33. doi:10.4049/jimmunol.170.7.3528

31. Yoshida M, Claypool SM, Wagner JS, Mizoguchi E, Mizoguchi A, Roopenian DC, et al. Human neonatal Fc receptor mediates transport of IgG into luminal secretions for delivery of antigens to mucosal dendritic cells. Immunity (2004) 20:769-83. doi:10.1016/j.immuni.2004.05.007

32. Belzer C, Liu Q, Carroll MC, Bry L. The role of specific IgG and complement in combating a primary mucosal infection of the gut epithelium. Eur J Microbiol Immunol (Bp) (2011) 1:311-8. doi:10.1556/EuJMI.1.2011.4.7

33. Bry L, Brenner MB. Critical role of T cell-dependent serum antibody, but not the gut-associated lymphoid tissue, for surviving acute mucosal infection with Citrobacter rodentium, an attaching and effacing pathogen. J Immunol (2004) 172:433-41. doi:10.4049/jimmunol.172.1.433

34. Yoshida M, Kobayashi K, Kuo TT, Bry L, Glickman JN, Claypool SM, et al. Neonatal Fc receptor for IgG regulates mucosal immune responses to luminal bacteria. J Clin Invest (2006) 116:2142-51. doi:10.1172/JCI27821

35. Ben Suleiman Y, Yoshida M, Nishiumi S, Tanaka H, Mimura T, Nobutani K, et al. Neonatal Fc receptor for IgG (FcRn) expressed in the gastric epithelium regulates bacterial infection in mice. Mucosal Immunol (2012) 5:87-98. doi:10.1038/mi.2011.53

36. Baker K, Qiao SW, Kuo TT, Aveson VG, Platzer B, Andersen JT, et al. Neonatal Fc receptor for IgG $(\mathrm{FcRn})$ regulates cross-presentation of IgG immune complexes by CD8-CD11b+ dendritic cells. Proc Natl Acad Sci U S A (2011) 108:9927-32. doi:10.1073/pnas.1019037108

37. Baker K, Rath T, Flak MB, Arthur JC, Chen Z, Glickman JN, et al. Neonatal Fc receptor expression in dendritic cells mediates protective immunity against colorectal cancer. Immunity (2013) 39:1095-107. doi:10.1016/j.immuni.2013. 11.003

38. Zhu X, Meng G, Dickinson BL, Li X, Mizoguchi E, Miao L, et al. MHC class I-related neonatal Fc receptor for IgG is functionally expressed in monocytes, intestinal macrophages, and dendritic cells. J Immunol (2001) 166:3266-76. doi:10.4049/jimmunol.166.5.3266

39. Qiao SW, Bergseng E, Molberg O, Jung G, Fleckenstein B, Sollid LM. Refining the rules of gliadin $\mathrm{T}$ cell epitope binding to the disease-associated DQ2 molecule in celiac disease: importance of proline spacing and glutamine deamidation. $J$ Immunol (2005) 175:254-61. doi:10.4049/jimmunol.175.1.254

40. Amigorena S, Savina A. Intracellular mechanisms of antigen cross presentation in dendritic cells. Curr Opin Immunol (2010) 22:109-17. doi:10.1016/j.coi.2010. 01.022

41. Tao MH, Morrison SL. Studies of aglycosylated chimeric mouse-human IgG. Role of carbohydrate in the structure and effector functions mediated by the human IgG constant region. J Immunol (1989) 143:2595-601.

42. Zalevsky J, Chamberlain AK, Horton HM, Karki S, Leung IW, Sproule TJ, et al. Enhanced antibody half-life improves in vivo activity. Nat Biotechnol (2010) 28:157-9. doi:10.1038/nbt.1601

43. Baker K, Qiao SW, Kuo T, Kobayashi K, Yoshida M, Lencer WI, et al. Immune and non-immune functions of the (not so) neonatal Fc receptor, FcRn. Semin Immunopathol (2009) 31:223-36. doi:10.1007/s00281-009-0160-9

44. Bitonti AJ, Dumont JA, Low SC, Peters RT, Kropp KE, Palombella VJ, et al. Pulmonary delivery of an erythropoietin $\mathrm{Fc}$ fusion protein in non-human primates through an immunoglobulin transport pathway. Proc Natl Acad Sci U S A (2004) 101:9763-8. doi:10.1073/pnas.0403235101

45. Israel EJ, Taylor S, Wu Z, Mizoguchi E, Blumberg RS, Bhan A, et al. Expression of the neonatal Fc receptor, FcRn, on human intestinal epithelial cells. Immunology (1997) 92:69-74. doi:10.1046/j.1365-2567.1997.00326.x

46. Dumont JA, Bitonti AJ, Clark D, Evans S, Pickford M, Newman SP. Delivery of an erythropoietin-Fc fusion protein by inhalation in humans through an immunoglobulin transport pathway. J Aerosol Med (2005) 18:294-303. doi:10.1089/jam.2005.18.294

47. Bitonti AJ, Dumont JA. Pulmonary administration of therapeutic proteins using an immunoglobulin transport pathway. Adv Drug Deliv Rev (2006) 58:1106-18. doi:10.1016/j.addr.2006.07.015
48. Low SC, Nunes SL, Bitonti AJ, Dumont JA. Oral and pulmonary delivery of FSH-Fc fusion proteins via neonatal Fc receptor-mediated transcytosis. Hum Reprod (2005) 20:1805-13. doi:10.1093/humrep/deh896

49. Vallee S, Rakhe S, Reidy T, Walker S, Lu Q, Sakorafas P, et al. Pulmonary administration of interferon Beta-la-fc fusion protein in non-human primates using an immunoglobulin transport pathway. JInterferon Cytokine Res (2012) 32:178-84. doi:10.1089/jir.2011.0048

50. Pridgen EM, Alexis F, Kuo TT, Levy-Nissenbaum E, Karnik R, Blumberg RS, et al. Transepithelial transport of Fc-targeted nanoparticles by the neonatal fc receptor for oral delivery. Sci Transl Med (2013) 5:213ra167. doi:10.1126/scitranslmed. 3007049

51. Grubb JH, Vogler C, Tan Y, Shah GN, MacRae AF, Sly WS. Infused Fc-tagged betaglucuronidase crosses the placenta and produces clearance of storage in utero in mucopolysaccharidosis VII mice. Proc Natl Acad Sci U S A (2008) 105:8375-80. doi:10.1073/pnas.0803715105

52. Chen P, Li C, Lang S, Zhu G, Reheman A, Spring CM, et al. Animal model of fetal and neonatal immune thrombocytopenia: role of neonatal Fc receptor in the pathogenesis and therapy. Blood (2010) 116(18):3660-8. doi:10.1182/ blood-2010-05-284919

53. Li C, Piran S, Chen P, Lang S, Zarpellon A, Jin JW, et al. The maternal immune response to fetal platelet GPIbalpha causes frequent miscarriage in mice that can be prevented by intravenous IgG and anti-FcRn therapies. J Clin Invest (2011) 121:4537-47. doi:10.1172/JCI57850

54. Maidji E, McDonagh S, Genbacev O, Tabata T, Pereira L. Maternal antibodies enhance or prevent cytomegalovirus infection in the placenta by neonatal FC receptor-mediated transcytosis. Am J Pathol (2006) 168:1210-26. doi:10.2353/ ajpath.2006.050482

55. Ye L, Zeng R, Bai Y, Roopenian DC, Zhu X. Efficient mucosal vaccination mediated by the neonatal Fc receptor. Nat Biotechnol (2011) 29:158-63. doi:10.1038/nbt.1742

56. Lu L, Palaniyandi S, Zeng R, Bai Y, Liu X, Wang Y, et al. A neonatal Fc receptortargeted mucosal vaccine strategy effectively induces HIV-1 antigen-specific immunity to genital infection. J Virol (2011) 85:10542-53. doi:10.1128/JVI. 05441-11

57. Kacskovics I, Cervenak J, Erdei A, Goldsby RA, Butler JE. Recent advances using FcRn overexpression in transgenic animals to overcome impediments of standard antibody technologies to improve the generation of specific antibodies. MAbs (2011) 3:431-9. doi:10.4161/mabs.3.5.17023

58. Cong Y, Feng T, Fujihashi K, Schoeb TR, Elson CO. A dominant, coordinated T regulatory cell-IgA response to the intestinal microbiota. Proc Natl Acad Sci U S A (2009) 106:19256-61. doi:10.1073/pnas.0812681106

59. Leach JL, Sedmak DD, Osborne JM, Rahill B, Lairmore MD, Anderson CL. Isolation from human placenta of the IgG transporter, FcRn, and localization to the syncytiotrophoblast: implications for maternal-fetal antibody transport. $J$ Immunol (1996) 157:3317-22.

60. Simister NE, Story CM. Human placental Fc receptors and the transmission of antibodies from mother to fetus. J Reprod Immunol (1997) 37:1-23. doi:10.1016/S0165-0378(97)00068-5

61. Simister NE, Story CM, Chen HL, Hunt JS. An IgG-transporting Fc receptor expressed in the syncytiotrophoblast of human placenta. Eur J Immunol (1996) 26:1527-31. doi:10.1002/eji.1830260718

62. Dumont JA, Liu T, Low SC, Zhang X, Kamphaus G, Sakorafas P, et al. Prolonged activity of a recombinant factor VIII-Fc fusion protein in hemophilia A mice and dogs. Blood (2012) 119:3024-30. doi:10.1182/blood2011-08-367813

63. Mahlangu J, Powell JS, Ragni MV, Chowdary P, Josephson NC, Pabinger I, et al. Phase 3 study of recombinant factor VIII Fc fusion protein in severe hemophilia A. Blood (2014) 123:317-25. doi:10.1182/blood-2013-10-529974

64. Powell JS, Pasi KJ, Ragni MV, Ozelo MC, Valentino LA, Mahlangu JN, et al. Phase 3 study of recombinant factor IX Fc fusion protein in hemophilia B. N Engl J Med (2013) 369:2313-23. doi:10.1056/NEJMoa1305074

65. Powell JS, Josephson NC, Quon D, Ragni MV, Cheng G, Li E, et al. Safety and prolonged activity of recombinant factor VIII Fc fusion protein in hemophilia A patients. Blood (2012) 119:3031-7. doi:10.1182/blood-2011-09-382846

66. Shapiro AD, Ragni MV, Valentino LA, Key NS, Josephson NC, Powell JS, et al. Recombinant factor IX-Fc fusion protein (rFIXFc) demonstrates safety and prolonged activity in a phase $1 / 2$ a study in hemophilia B patients. Blood (2012) 119:666-72. doi:10.1182/blood-2011-07-367003 
67. Baker K, Rath T, Lencer WI, Fiebiger E, Blumberg RS. Cross-presentation of IgG-containing immune complexes. Cell Mol Life Sci (2013) 70(8):1319-34. doi:10.1007/s00018-012-1100-8

68. Akilesh S, Petkova S, Sproule TJ, Shaffer DJ, Christianson GJ, Roopenian D. The MHC class I-like Fc receptor promotes humorally mediated autoimmune disease. J Clin Invest (2004) 113:1328-33. doi:10.1172/JCI18838

69. Hansen RJ, Balthasar JP. Intravenous immunoglobulin mediates an increase in anti-platelet antibody clearance via the FcRn receptor. Thromb Haemost (2002) 88:898-9.

70. Li N, Zhao M, Hilario-Vargas J, Prisayanh P, Warren S, Diaz LA, et al. Complete FcRn dependence for intravenous Ig therapy in autoimmune skin blistering diseases. J Clin Invest (2005) 115:3440-50. doi:10.1172/JCI24394

71. Liu L, Garcia AM, Santoro H, Zhang Y, McDonnell K, Dumont J, et al. Amelioration of experimental autoimmune myasthenia gravis in rats by neonatal FcR blockade. J Immunol (2007) 178:5390-8. doi:10.4049/jimmunol.178.8. 5390

72. Liu Z, Roopenian DC, Zhou X, Christianson GJ, Diaz LA, Sedmak DD, et al. Beta2-microglobulin-deficient mice are resistant to bullous pemphigoid. J Exp Med (1997) 186:777-83. doi:10.1084/jem.186.5.777

73. Nimmerjahn F, Ravetch JV. The antiinflammatory activity of IgG: the intravenous IgG paradox. J Exp Med (2007) 204:11-5. doi:10.1084/jem.20061788

74. Nimmerjahn F, Ravetch JV. Anti-inflammatory actions of intravenous immunoglobulin. Annu Rev Immunol (2008) 26:513-33. doi:10.1146/annurev. immunol.26.021607.090232

75. Patel DA, Puig-Canto A, Challa DK, Perez Montoyo H, Ober RJ, Ward ES. Neonatal Fc receptor blockade by $\mathrm{Fc}$ engineering ameliorates arthritis in a murine model. J Immunol (2011) 187:1015-22. doi:10.4049/jimmunol.1003780

76. Petkova SB, Akilesh S, Sproule TJ, Christianson GJ, Al Khabbaz H, Brown AC, et al. Enhanced half-life of genetically engineered human IgG1 antibodies in a humanized FcRn mouse model: potential application in humorally mediated autoimmune disease. Int Immunol (2006) 18:1759-69. doi:10.1093/intimm/ dxl110

77. Mezo AR, McDonnell KA, Hehir CA, Low SC, Palombella VJ, Stattel JM, et al. Reduction of IgG in nonhuman primates by a peptide antagonist of the neonatal Fc receptor FcRn. Proc Natl Acad Sci U S A (2008) 105:2337-42. doi:10.1073/pnas.0708960105

78. Mezo AR, Sridhar V, Badger J, Sakorafas P, Nienaber V. X-ray crystal structures of monomeric and dimeric peptide inhibitors in complex with the human neonatal Fc receptor, FcRn. J Biol Chem (2010) 285:27694-701. doi:10.1074/jbc.M110. 120667

Conflict of Interest Statement: The authors declare that the research was conducted in the absence of any commercial or financial relationships that could be construed as a potential conflict of interest.

Received: 22 August 2014; accepted: 10 December 2014; published online: 05 January 2015.

Citation: Rath T, Baker K, Pyzik M and Blumberg RS (2015) Regulation of immune responses by the neonatal $F c$ receptor and its therapeutic implications. Front. Immunol. 5:664. doi: 10.3389/fimmu.2014.00664

This article was submitted to Immunotherapies and Vaccines, a section of the journal Frontiers in Immunology.

Copyright (C) 2015 Rath, Baker, Pyzik and Blumberg. This is an open-access article distributed under the terms of the Creative Commons Attribution License (CC BY). The use, distribution or reproduction in other forums is permitted, provided the original author(s) or licensor are credited and that the original publication in this journal is cited, in accordance with accepted academic practice. No use, distribution or reproduction is permitted which does not comply with these terms. 